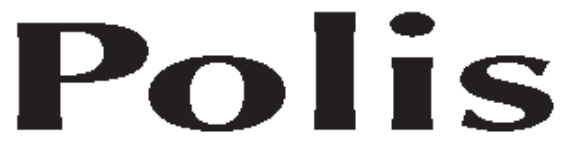

\title{
De la competencia a la complementación ¿Un nuevo paradigma en la economía?
}

\author{
Graciela Mazorco Irureta*
}

Resumen: Bajo un manto de humanismo, las energías ideológicas del sistema persiguen que los marginados acepten que el capitalismo y su economía de mercado son la única alternativa y declinen la lucha por un mundo mejor mientras creen que están preservando sus valores culturales. Aunque actualmente occidente promueve la complementación y la solidaridad como valores rectores de los procesos económicos, no pasa de ser una retórica discursiva que no va a cambiar nada mientras no se muten los fundamentos filosóficos que sostienen al sistema capitalista, que basa las relaciones sociales y mercantiles en el antagonismo y la competencia. El llamado social a hacer «otro mundo posible» requiere la reconfiguración paradigmática de las ciencias económicas, entre otras, para hacer posible la constitución de una sociedad pluricultural y plurieconómica, en la que puedan autodeterminarse distintas modalidades de producir y consumir según las diversas cosmovisiones que la pueblan. Nuestro aporte a este propósito es el planteamiento de una economía inter e intracultural.

Palabras clave: economía, competencia, complementación, interculturalidad, intraculturalidad.

\section{From competition to complementation. A new paradigm in economy?}

Abstract: Under a pretence of humanism, the ideological energies of the system pursue that the marginalized accept that capitalism one and its market economy are the only alternative, so they will decline to fight for a better world while they believe they are preserving their cultural values. Although at present the western world promotes complementation and solidarity as main values for economic processes, it is no more than a discursive rhetoric which is going to change nothing as long as the philosophical bases that maintain to the capitalist system mutate, since commercial and social relations are based in the antagonism and competition. The social appeal to do "another possible world" requires the paradigmatic reconfiguration of economics, among others, to make possible the constitution of a multicultural and plurieconomic society, in which different modalities of production and consumption can selfdetermine according to the diverse worldviews which live within it. Our contribution to this purpose is the proposal of an inter and intracultural economy.

\footnotetext{
*Universidad Mayor de San Simón, Cochabamba, Bolivia. Email: gramas@ faces.umss.edu.bo.
} 
Key words: economy, competition, complementation, interculturality, intraculturality.

\section{El recambio discursivo ante el fracaso neoliberal}

Estamos viviendo hoy, en octubre de 2008, "la crisis financiera desatada en Estados Unidos [:] un gran caos que arrastra en espiral a la economía mundial. [...] Los mercados globales de créditos están paralizados, la pirámide ficticia de valores de las viviendas se ha derrumbado, rescates y compras inesperadas son ejecutados por firmas privadas y gobiernos." (Alonso 2008). A nivel mundial, tanto la derecha como la izquierda predicen en estos momentos el fin del modelo económico perverso instaurado con la ideología neoliberal.

Sin embargo esa sentencia no nos resulta novedosa a los latinoamericanos. Con mucha anticipación, en el tercer mundo ya se había asumido desde los años noventa que los países subdesarrollados no debían insistir en el neoliberalismo, ya que la mayor competencia, el comercio libre y el Estado frágil habían conducido a la hecatombe económica y a la fragmentación social. Las reformas macroeconómicas promovidas por el neoliberalismo no funcionaron, porque -se dice- faltó un Estado capaz de articular a los actores estratégicos. El modelo neoliberal demostró que el desarrollo era inviable con un Estado reducido y unas empresas débiles. La desestatización (privatización de empresas públicas y reducción del gasto estatal), la desprotección (apertura de mercados a productos y capitales internacionales) y la des-regularización (liberalización de los mercados internos) que el neoliberalismo utilizó para acabar con las economías cerradas, abriéndolas a la competencia internacional, no han garantizado la eficiencia de los mercados.

Se esperaba que la apertura de mercados favoreciera la especialización y mejorara la eficiencia industrial, ya que por efectos de la competencia se eliminarían las empresas ineficientes. La propaganda neoliberal hizo creer que la libre importación de productos permitiría a los productores locales el aprendizaje de métodos de producción más eficientes, y la exportación alentaría la incursión de nuevos empresarios, generando economías de escala por mayores volúmenes de producción, así como economías de aglomeración en caso de concentración geográfica de los productores (Pelupessy 2002). En los hechos, no hubo una inserción competitiva $\mathrm{y}$, por el contrario, se desarticularon las cadenas industriales que medianamente se habían formado en el período de industrialización por sustitución de importaciones, dirigida, sobre todo, al mercado interno. La inclusión de empresas de Latinoamérica en cadenas internacionales de producción y comercialización no ha favorecido el desarrollo autosostenible. Más bien ha tenido un 
efecto empobrecedor sobre los pequeños productores, porque ocuparon una posición subordinada en la cadena, aceptando subcontrataciones altamente dependientes de las firmas multinacionales. Así, desestructuraron sus propias redes de distribución hacia el mercado interno y externo, se especializaron demasiado, volviéndose vulnerables a los cambios de la demanda, y perdieron la posibilidad de desarrollar o adaptar tecnologías, al asumir las que eran impuestas por los contratistas (Bekerman y Cataife 2004).

Ha quedado demostrado el alto costo social y medioambiental del crecimiento económico en los países desarrollados, así como la inviabilidad de que los pueblos pobres transiten por la vía del libre mercado hacia el desarrollo industrial del Primer Mundo, porque se enfrentan en condiciones asimétricas al poder económico-político que dirige el sistema capitalista.

Ahora queda claro que las empresas establecen relaciones que exceden el puro ámbito de mercado. Los acuerdos y alianzas entre firmas poderosas prevalecen sobre las relaciones espontáneas de mercado que la teoría neoclásica veía determinadas por el encuentro de la oferta y la demanda en torno a la función equilibradora de los precios, a través de puras relaciones mercantiles de compra-venta, en condiciones de competencia definida por el igual acceso de participantes racionales a la información y a los recursos. Actualmente es visible que los agentes económicos coordinan y negocian precios y condiciones para reducir, por un lado, la incertidumbre provocada por la falta de acceso a información perfecta $\mathrm{y}$, por otro, las asimetrías que provienen del desigual acceso a mercados y recursos, incluido el desigual acceso a información sobre el funcionamiento de los mercados. En lugar de relaciones mercantiles nos encontramos con un proceso negociado entre empresas en condiciones de asimetría de poder. La capacidad de negociación política, económica y comercial determina el poder que rige las relaciones de mercado y constituye barreras de entrada que aumentan la rentabilidad a costa de reducir la competitividad. Más que de eficiencia de los mercados, se habla hoy de desigualdades de poder (Ibíd).

La dinámica acelerada y convulsiva de un entorno global marcado por las asimetrías que han signado el fracaso del modelo neoliberal en el Tercer Mundo, ${ }^{1}$ junto con la presión de los movimientos sociales, indígenas y ecologistas que claman por «otro mundo posible», exigen una salida estabilizadora, para la cual, la inteligencia que dirige el sistema ha echado mano al componente ideológico y ha creado un sentimiento fuertemente apuntalado por el

\footnotetext{
${ }^{1}$ El fracaso del modelo neoliberal en Latinoamérica se reflejó en el no-crecimiento económico, la descapitalización, el despojo de nuestras riquezas, el desempleo, la pobreza, el desplome del modelo de industrialización sustitutiva de importaciones, la crisis de la deuda, el debilitamiento de las instituciones democráticas, la desigualdad social y económica, una economía más dependiente, vulnerable y extranjerizada, junto con un estado impotente para poner coto al capital imperialista (Zegada 2004).
} 
discurso de que no hay alternativa al capitalismo de libre mercado. Concomitantemente, y a partir del 11 de septiembre de 2001, ha reforzado el componente político-militar, con lo que reconfigura el neoliberalismo en un neo-neoliberalismo armado e intervencionista, fuertemente anti-democrático, disfrazado de humanismo anti-terrorista, que pretende desarmar los sistemas de defensa de todos los países del sur y el este que representan un obstáculo a las pretensiones norteamericanas de dominio del planeta.

En lo ideológico, la imposición de la monocultura occidental provocó resistencias, cerramientos y fundamentalismos fragmentadores, peligrosos para el avance del sistema capitalista, porque más allá de las luchas de clases vinieron las guerras culturales. En 1998 la UNESCO reconoció que la globalización une culturas, pero lleva incorporado el riesgo de uniformarlas, y propuso, para frenar los conflictos mundiales, que el desarrollo debe basarse en el respeto a las identidades culturales y fomentar una cultura de paz, asentada en la tolerancia entre diferentes para hacer posible la convivencia armónica (Ramírez 2003). Bajo esa lógica, la propuesta intercultural postmoderna promueve el sincretismo cultural que integra. Pero la integración social, el diálogo y el consenso social que el neoneoliberalismo necesita en torno a las reglas del libre mercado y a la apertura económica demandan hacer compatibles las tradiciones comunitarias con los valores occidentales (supuestamente universales) que, muy por el contrario del comunitarismo, hacen de la competencia la modalidad económica y política por excelencia.

En esa línea, el desarrollo endógeno ${ }^{2}$ se presenta como una alternativa ante el modo de vida capitalista, pretendiendo integrar a la población excluida y adoptar nuevos estilos de vida y de consumo a partir de valores comunitarios, cooperativos y solidarios, respetando la cultura de cada pueblo (Sánchez 2004). En lo sociocultural, se aspira a la integración de «los actores económicos y sociales (comunidad que produce) con las instituciones locales, formando un sistema de relaciones que incorporan los valores de la sociedad al proceso de desarrollo». ${ }^{3}$ «Debe tener su origen desde el interior de la misma sociedad e involucrar a todos los actores, interesados y afectados, sobre una determinada forma de definir y alcanzar lo que se considera bueno para esa sociedad [respondiendo a] un cierto modo de ser cultural» (Pilonieta s/f: 23). «En el proceso de toma de decisiones es necesaria la promoción de una buena red asociativa, la dignificación de los sectores sociales

\footnotetext{
${ }^{2}$ El desarrollo endógeno destaca la construcción local del desarrollo, de abajo hacia arriba, limitando la dependencia con respecto a los agentes externos, en contra de las tendencias anteriores que pretendían imponerlo de arriba hacia abajo, merced a la difusión de innovaciones tecnológicas provenientes del Primer hacia el Tercer Mundo. El desarrollo endógeno, en cambio, procura potenciar las capacidades internas de una nación, región o comunidad local, bajo el supuesto de que el crecimiento, antes que de factores exógenos, depende las decisiones locales de ahorro e inversión, que favorecen la acumulación de tres capitales: capital físico, capital humano y capital técnico (conocimientos). (Camargo 2007).

3 "Desarrollo Endógeno: desde adentro, desde la Venezuela profunda".
} 
organizados y el fomento del asociacionismo. Estos aspectos de organización social forman parte del llamado "Capital Social", [definido como] "el conjunto de características de organización social, tales como redes asociativas, normas establecidas y grado de confianza que facilitan la coordinación y cooperación para el beneficio mutuo".» (Camargo 2007).

Sin embargo, la revalorización de las particularidades culturales no admite la diferencia cultural que resiste integrarse al mercado. Por lo tanto, estamos ante una nueva homogeneización que asegura la integración al mercado de los que quedaron afuera y luchan por «otro mundo posible». Negando cualquier posibilidad a otras visiones de producción, de consumo y de vida, el desarrollo endógeno es el encargado de promover, negando la diferencia cultural, los códigos modernos que inducirán «a los agentes locales (la comunidad) a usar eficientemente los factores productivos y a alcanzar los niveles de productividad que les permiten ser competitivos», ${ }^{4}$ siendo que estos son códigos monoculturales ligados indefectiblemente a la economía capitalista.

El respeto a la diferencia cultural es una parodia. Una vez que el imperialismo ha convencido a casi todo el mundo subdesarrollado de que no es posible aislarse económicamente, orientándose hacia adentro y cerrando fronteras, las diferencias culturales que habrán de respetarse serán sólo aquéllas útiles para vencer las renuencias a profundizar la apertura de mercados y declinar la lucha por «otro mundo posible», mientras se cree estar preservando los valores endógenos.

Irónicamente, el discurso endogenista apela a valores no-capitalistas: la complementación en los mercados, la solidaridad y la reciprocidad-todos ellos atribuidos a aquellas sociedades en las que los equilibrios sociedad-naturaleza prevalecen por sobre las relaciones de mercado-, para apuntalar objetivos capitalistas. Efectivamente, el objetivo de consolidar un desarrollo con estilo propio, es decir, desde los propios valores, cosmovisiones e identidades culturales de los propios actores, es una ilusoria contradicción, ya que «desarrollo» y «mercado» son códigos de una específica identidad cultural: la occidental, y no se condicen con aquellas identidades originarias que conciben otras modalidades de existencia, en correspondencia con otras visiones de mundo en las que la producción, la intermediación y el consumo adquieren un cariz muy diferente al que les atribuye la economía capitalista.

El discurso de la integración social tiene el objetivo de que los Estados, las entidades privadas y las sociedades marginadas por el sistema capitalista aprueben sin oposición ni resistencia el modelo de desarrollo occidental. En ese marco, la integración sigue siendo subordinada, porque las prácticas comunitarias no mercantiles serán impracticables en la

\footnotetext{
${ }^{4}$ Ibíd. Énfasis nuestro.
} 
medida en que han sido transformadas en capital social y cultural, ${ }^{5}$ integradas al circuito del mercado, con lo cual se mantiene hegemónico el sistema capitalista.

En cuanto a la supuesta solidaridad comunitaria a la cual se apela, no deja de ser una retórica que encubre que la solidaridad es, en esencia, cristiana y occidental, usada por el modelo capitalista y también el socialista para sus asistencialismos, sin cambiar la esencia del sistema. Lo que se mantiene imperturbado es el fundamento del hombre antropocéntrico que puede echar mano a todo lo que existe a su alrededor, visto como «recurso» material, social o cultural para fines de acumulación de riqueza y capital. En ningún momento el discurso interculturalista alude al no-antropocentrismo de las culturas tradicionales, que asigna a los elementos de la naturaleza y al cosmos la condición de hermanos y hermanas del hombre y de la mujer.

Desde otras visiones de mundo no se trata de integrar la cultura de producción local a los parámetros de mercado, que es lo que proponen las diversas teorías del desarrollo. Más bien hay que ir abriendo espacios a una economía plural que admita, junto al ámbito de la economía capitalista, otras modalidades de economías: de mercado, como las socialistas y las solidarias, y de no-mercado, como las originarias, en las que puedan desarrollarse modos de existencia (no sólo de trabajo) compatibles con otras concepciones de mundo.

Para lograr una economía plural que permita satisfacer a distintas visiones de mundo, incluida la capitalista, sin imposiciones hegemónicas, es preciso comprender que todo discurso responde a un fundamento filosófico, desde el cual se percibe la realidad y se estructuran las acciones humanas. En ese sentido, los conceptos de competitividad, mercado y desarrollo trasuntan una ideología que impone una modalidad particular de pensar y de hacer economía, y truncan, en consecuencia, cualquier modo alternativo de vivir, producir y consumir. Toda vez que las teorías económicas provienen de la máxima jerarquía intelectual que establece occidente: el mundo científico del Primer Mundo, las mismas son compatibles con su propia visión de mundo y no dejan de provocar una involución en las comunidades originarias al destruir su identidad ancestral para implantar la lógica devoradora del capitalismo. Es preciso entonces romper el preconcepto de que únicamente occidente hace filosofía y comenzar a desenterrar las filosofías originarias, ${ }^{6}$ así como las teorías económicas y teorías de todo tipo que de ellas se derivan.

\footnotetext{
${ }^{5}$ El capital social viene dado por la capacidad de coordinación de los actores sociales, la cual depende de la existencia de redes que funcionan en base a la confianza y las normas, y sirve para mejorar la eficiencia de la sociedad (Peña 2006), en la medida en que la confianza ahorra conflictos y favorece la inversión. El capital cultural es la suma de valores compartidos, y, por tanto, promueve la cohesión social.

${ }^{6}$ Entendemos por originaria, aquella concepción de la realidad como un todo entretejido, que existe en el planeta desde tiempos ancestrales y fue en gran parte enterrada y/o subalternizada por la colonización europea.
} 
Aunque en la actualidad Occidente promueve nuevos valores como la complementación y la solidaridad para regir los procesos económicos, no pasa de ser una retórica discursiva que no va a cambiar nada mientras no se muten los fundamentos filosóficos que sostiene el sistema capitalista, basado en la competencia que antagoniza a los participantes en el mercado y a éstos con la naturaleza. Para hacer posible otras formas de vida y economía que condigan con otras visiones de mundo, es necesario, precisamente, hacer presentes los fundamentos filosóficos que subyacen en ellas, traerlos al lenguaje cotidiano e incorporarlos en el discurso filosófico y científico, dando lugar a pluralidades filosóficas y científicas concomitantes con las plurales prácticas económicas que se quiere viabilizar. A continuación hacemos una revisión de los diferentes fundamentos filosóficos sobre los cuales se edifican los conceptos y prácticas, por un lado, de la economía de mercado, y por otro, de la economía originaria que todavía está presente en algunas prácticas mercantiles locales y en ciertos espacios de nuestras comunidades indígenas en las que el ser humano no se separa de la realidad, ni tampoco aparta la razón de otras potencias, como los sueños, la intuición, el sentimiento, las visiones y otras, con las que, en unidad con la razón, se conoce la realidad.

\section{Fundamentos filosóficos de la economía de mercado}

La contradicción es el principio básico que, en la concepción del mundo que occidente ha sistematizado, propugna la competencia como eje rector de la economía capitalista.

La economía de mercado es un concepto-vivencia que responde a una concepción de la naturaleza y el cosmos como algo externo al ser humano, estableciendo, en el inicio, la separación fundamental entre el hombre y la realidad. Asigna antropocéntricamente al género humano el rol central en el existir y transcurrir del universo, el cual queda constituido en su entorno, puesto en condición de útil o instrumento a su servicio. Asignamos a esta filosofía o concepción de la realidad el denominativo de filosofía de la no-unidad o de la separación hombre/naturaleza, y no es la única manera de pensar sistemáticamente la realidad. Existe y existió desde antaño otra filosofía que traduce una modalidad alternativa de ser-sentir-saber-hacer de lo humano unido a la naturaleza, al cosmos y a la totalidad de la realidad. Esta filosofía de la unidad fue y es asumida por todos los individuos del planeta que se sienten hermanados con la madre naturaleza y no asimilaron ni asimilan la imposición colonizadora y recolonizadora de la estructura del pensamiento dicotómico de occidente.

La filosofía de la no-unidad admite variantes paradigmáticas; es decir, modelos conceptuales-metodológicos para analizar la realidad. Uno de ellos modeliza la realidad como una máquina, cuyo conocimiento requiere el análisis o descomposición de la totalidad en sus partes componentes. Es el mecanicismo-reduccionismo, que supone que la observación del funcionamiento de las partes aisladas producirá, por agregación, el 
discernimiento de la totalidad. Otra, más actual, la piensa como un tejido donde todo está entrelazado y no admite conocimientos parciales, ya que el todo es más que la suma de las partes. Es el holismo sistémico, que centra su atención en las múltiples relaciones entre las partes y no tolera la simple linealidad causa-efecto del pensamiento mecanicista. En ambos casos, sea mecánica o tejida, la realidad es puesta como algo externo al hombre. Se ponen en contradicción la naturaleza y la cultura: la cultura es el acto que humaniza la naturaleza; esto es, la instrumentaliza y domestica al servicio del hombre, negándole inteligencia y autodeterminación. Estos últimos atributos son concedidos únicamente al ser humano en función de otra dicotomía: el racionalismo, que surge de divorciar y jerarquizar el pensar sobre el sentir.

La dicotomía y la jerarquía configuran un esquema mental generalizado con el cual la ciencia interpreta el universo como un proceso regido esencialmente por la evolución jerarquizante y la competencia entre antagónicos. El perfeccionismo evolutivo es el sustrato del pensamiento lineal presente en la biología, al considerar antropocéntricamente al ser humano como lo más evolucionado de la naturaleza; en la antropología, al pensar etnocéntricamente en la existencia de sociedades «primitivas» o «salvajes» que todavía no han evolucionado hacia el estadio superior de la civilización y, por ello, su conocimiento tiene el estatus de «pre-científico». El concepto de progreso de la teoría económica es el equivalente de la idea de evolución de la ciencia biológica. El desarrollo es la expresión del progreso y de la modernidad; los desarrollados están en la escala superior y se considera la existencia periférica de sociedades atrasadas o subdesarrolladas que deben recorrer el camino del progreso para evolucionar hacia la perfección concebida como bienestar o nivel de vida alto que caracteriza a las sociedades altamente industrializadas.

En esta visión de mundo, la evolución funciona en base a la competencia. La economía está fuertemente influida por la biología, en la que el azar se convirtió en el rector de la evolución y destronó al determinismo de dios y de las leyes naturales. Darwin proponía que era la competencia (la lucha por la vida) la que guiaba la evolución. El organismo más fuerte -el más adaptado al entorno- era algo así como escogido por la selección natural para sobrevivir y procrear la especie mejorada o perfeccionada. En $« E l$ origen de las especies», Darwin equipara la vida social a la natural, afirmando que la selección natural también opera para que los individuos más competitivos sobrevivan, puesto que se adaptan mejor al entorno socio-económico en que viven. Como el que sobrevive es el mejor adaptado, queda garantizado el progreso o perfeccionamiento continuo de la especie por ellos procreada, que es, en la época de Darwin, la sociedad industrial. Para el economista Hayeck ${ }^{7}$ la especie perfeccionada será la sociedad capitalista neoliberal, que surge por azar (sin que nadie la haya premeditado) del juego competitivo entre los individuos. En esta pelea los más competitivos obtendrán, por pura suerte, resultados exitosos y sobrevivirán, originando que los demás individuos imiten los

${ }^{7}$ Junto con Von Mises y otros, Von Hayeck plantea en 1947 la doctrina neoliberal. 
comportamientos que han probado ser mejor adaptados. (Sorman 1991).

De ese modo, la sociedad capitalista es incuestionablemente defendida como lo mejor, porque es lo que ahora tenemos, y la teoría evolutiva dice que lo que tenemos sólo puede ser resultado de un perfeccionamiento continuo. Al mismo tiempo, como la perfección ha resultado de la modalidad de «lucha por la vida» denominada competencia, este enfrentamiento destructivo de los individuos en el mercado es irrefutablemente patrocinado como el óptimo comportamiento social, de lo cual resulta que la modalidad de vida más evolucionada impone que, para sobrevivir, hay que destruir al otro, al enemigo. Este tipo de razonamiento muestra que la ideología capitalista recurre a los más tautológicos artificios para defender su verdad. El precepto de que el sistema de mercado es lo mejor no admite negación, porque la evolución siempre es, por definición, perfeccionista.

En la postmodernidad se cuestionan las bondades del progreso y el dogma de la racionalidad por haber destruido las identidades culturales de las sociedades tradicionales, sus relaciones productivas de equilibrio ecológico con la naturaleza y sus redes de solidaridad comunitaria, causando el desempleo, la inflación, la pobreza, el desastre ecológico, la violencia y la deshumanización, los cuales no pueden precisamente ser catalogados como procesos evolutivos, sino involutivos. La razón científica -alegan los postmodernos- descalificó a todas las otras formas de conocimiento propias de las culturas ancestrales. Se las obligó a superar sus ideas, creencias, costumbres y prácticas de vida, porque ellas, supuestamente, eran la causa de su estancamiento en un nivel que occidente calificó como de subsistencia; es decir, de poca producción y poco consumo, lo cual no es malo en sí mismo, salvo que poco sirve a la perpetuación del sistema capitalista (Sachs 1997). Otras formas de educación diferentes a la escolarización domesticadora, otros modos de curar basados en la sabiduría tradicional y otras maneras de producir que responden a una unidad cosmológica con la tierra y que nada tienen que ver con el uso de la tecnología depredadora, serán desconocidas por la modernidad, pero revalorizadas en la postmodernidad.

Las críticas tan duras al desarrollo volvieron necesaria su humanización, incorporando variables cualitativas. Ya no se debe buscar el puro crecimiento económico material, sino la mejora de la calidad de vida de las personas, que también necesitan bienes intangibles o culturales, como salud psíquica, felicidad, libertad, seguridad, así como integrarse a la sociedad y armonizarse con la naturaleza, entre otros (Tapia 2003). Sin embargo, el enfoque de desarrollo humano ${ }^{\mathbf{8}}$ sigue siendo modernización hegemonizante,

\footnotetext{
${ }^{8}$ El enfoque de Desarrollo Humano da prioridad a las personas antes que al crecimiento económico. Enfatiza el desarrollo del potencial humano para que la gente viva una vida larga y saludable, tenga educación y recursos para vivir decentemente. Son importantes elementos como «la participación, la seguridad, la sostenibilidad, las garantías de los derechos humanos, para gozar de respeto por sí mismo, potenciación y una sensación de pertenecer a una comunidad». (PNUD s/f.). «Por ello hay necesidad de considerar el desarrollo humano mano a mano con el desarrollo social. El desarrollo humano requiere trabajar a través de los niveles
} 
puesto que sus indicadores son formulados desde el Primer Mundo y responden al modelo de ser humano impuesto por la cultura occidental. (Ramírez 2003).

Al pensamiento sistémico le tocará limar las punzantes aristas de la competitividad, sentando nuevos fundamentos epistemológicos que condicen con una visión más humanista de la economía, pero que, pese a todo, no contrarían el sistema capitalista. La teoría sistémica que domina durante los 40-70 está ligada al estructural-funcionalismo, ${ }^{9}$ pero en los años setenta se revitaliza, incorporando un concepto de la denominada segunda cibernética: la auto-organización; esto es, la relación que se da entre los elementos de un sistema y que le permite a éste existir de manera autónoma. La auto-organización está atada al concepto de red, entendida a su vez como el patrón circular de la vida. La red rompe con el pensamiento lineal y permite ver al sistema como un aprendiz capaz de corregir sus errores y autorregularse, es decir, auto-organizarse, haciendo aparecer órdenes espontáneos, no programados. Con ello se introduce, como factor fundamental, la autonomía que resquebraja los determinismos estructuralistas asociados al pensamiento sistémico de la época anterior (Mazorco 2008).

El pensamiento holístico-sistémico, que también considera al universo como algo externo al hombre, toma en cuenta la multidimensionalidad inabarcable de las variables que interactúan para configurar cualquier fenómeno, signadas además por causaciones recíprocas, lo cual hace imposible el determinismo mecanicista y reduce el conocimiento de la realidad al nivel de una simple aventura de predicciones probabilísticas. ${ }^{10} \mathrm{La}$ incertidumbre y el caos son apuntalados por el pensamiento sistémico, recurriendo al concepto de auto-regulación, que describe cómo los sistemas se mantienen estables (en equilibrio) en el marco del permanente flujo (caos) de energía-materia que entra de y sale al exterior, situación que para la ciencia clásica era inasociable con el equilibrio, que ella

locales [de ahí su estrecha relación con el desarrollo endógeno], regionales, nacionales e internacionales, y con una amplia red de socios y contrapartes.» (CCD s/f.).

${ }^{9}$ El funcionalismo sirve para interpretar los hechos sociales fuera de las intenciones de los individuos: no se ocupa de personas, sino de estructuras; es decir, del conjunto de instituciones, como la familia, el Estado, el sistema legal, educativo, el mercado, etc. Son las relaciones estructurales las que configuran los fenómenos observables, y no los comportamientos específicos de los individuos.

${ }^{10}$ El reinado del determinismo y la certeza fue roto por Heisenberg y la mecánica cuántica, al establecer la dualidad partícula-onda. Cuanta mayor precisión tengamos en medir la posición de la partícula, con menor precisión se podrá medir su velocidad, y viceversa; esto es: posición y velocidad no pueden ser definidas por separado. El principio de incertidumbre gobierna desde entonces y no sólo el mundo de la física, sino todas las ciencias. Señala que si no podemos medir el estado presente del universo, menos vamos a predecir el futuro; a lo más, se puede predecir un cierto número de resultados posibles, cada uno con sus probabilidades asociadas (Hawking 1997). 
concebía como orden; es decir, conformado por estructuras estáticas. Fuera del equilibrio se produce la disipación o pérdida de energía que conduce, a través de un desorden (caos) creciente, al agotamiento del mundo. Para Prigogine, en cambio, la disipación es fuente de orden, ya que en situaciones de desequilibrio (caos) químico surgen espontáneamente organizaciones perfectamente ordenadas, a las que llamó estructuras disipativas porque consumen más energía que la organización anterior, o sea, son más desordenadas (Prigogine 1991). El cambio de una estructura (un orden) a otra (un nuevo orden) involucra una transformación de una modalidad de equilibrio a otra nueva. Este proceso ha sido denominado auto-regulación y auto-organización, y es concebido como un ciclo secuencial y permanente de orden-desorden-orden.

Esta secuencialidad demuestra que la linealidad sigue presente en el pensamiento sistémico, preñado de la racionalidad aristotélica que establece: «si P (causa), entonces Q (consecuencia)». La causalidad supone la linealidad secuencial de elementos o fenómenos separados. En contraposición -y aquí ya adelantamos algo del fundamento filosóficos alternativo que veremos más adelante-, la visión de la realidad como una unidad entre el ser humano y la totalidad capta la simultaneidad del orden y del caos, o de la partícula y la onda, en tanto se encuentran combinados e intracombinados, no pudiendo ser separados, pues se contienen mutuamente. Para esta filosofía, caos y orden son procesos donde la destrucción y la construcción coexisten; el nuevo orden contiene al destruido, el orden contiene al caos y viceversa. (Mazorco 2008).

El caos es introducido en la teoría económica por Fiedrich Von Hayeck, quien sostuvo que: «En la economía de mercado, así como en la naturaleza, el orden viene del caos: la armonización espontánea de millones de decisiones y de información conduce no al desorden, sino a un orden superior». No existe ningún mecanismo que permita registrar ni coordinar la infinitud de acciones y decisiones que, las más de las veces, responden a un juego de azar, antes que a un direccionamiento premeditado. De este modo, el crecimiento económico resulta de un proceso auto-regulado, y no tiene sentido que el Estado pretenda planificar la economía (Sorman 1991:188).

También la auto-regulación sistémica es apropiada por Hayeck para justificar el neoliberalismo. Para Hayeck, la lucha competitiva entre individuos produce comportamientos afortunados que luego son imitados por otros. De esa manera, por selección e imitación, se va generando espontáneamente (auto-reguladamente) un orden, sin que haya sido premeditado. A su criterio, el orden espontáneo se traduce en instituciones que no fueron planificadas ni inventadas, sino que surgieron por la selección social darwiniana. Entre ellas, la familia, la economía de mercado, la propiedad privada y el cumplimiento de los contratos serían el producto de una evolución en la que ciertos pueblos que respetaron la propiedad y los contratos se volvieron por pura suerte más prósperos; luego la selección natural escogió esos comportamientos favorables para la lucha competitiva y se constituyeron en la moral que sustenta la sociedad industrial capitalista 
(Sorman 1991). Gracias a estas instituciones «la sociedad occidental se volvió moral y, sin esta moralidad fundamental, el capitalismo no podría existir» (Ibíd.: 190).

Las declaraciones de Hayeck sugieren que el capitalismo es el camino evolutivo que la selección darwiniana escogió por su superioridad frente a otros modelos de vida, superioridad de la que deviene la moralidad que justifica las instituciones del mercado libre. Tal como expresa el biólogo japonés Motoo Kimura (1991), el darwinismo refleja y justifica la visión competitiva de la sociedad occidental $\mathrm{y}$, pretendiendo oponerse al determinismo, convierte a la selección natural en un nuevo determinismo, tal como una mano invisible que actúa según algún proyecto moral diseñado con una finalidad perfeccionista y convierte al capitalismo en algo así como el resultado de un propósito divino, es decir, de una premeditación contraria a la auto-regulación espontánea que propone el darwinismo social.

El pensamiento holístico-sistémico niega la competencia como elemento rector de la evolución. La complementación antes que la competencia aparece como la clave del proceso evolutivo que, por lo demás, no es perfeccionista. Efectivamente, los biólogos y neurocientífico chilenos Maturana y Varela, así como la bióloga norteamericana Margulis, señalan que la visión de la evolución biológica y social como una lucha competitiva en que la especie que ha perfeccionado sus características prevalecerá y se reproducirá en nuevas especies dominantes queda obsoleta, porque la realidad demuestra que no hay ni competencia, ni formas de vida superiores, ni jerarquías dominantes en los procesos de la naturaleza; solo hay complementación. Más aún, la vida es el fruto de la interacción y asociación entre organismos celulares. (Mazorco 2008).

\section{Fundamentos filosóficos para hacer «otra economía posible»}

Sintetizamos esta propuesta filosófica alternativa diciendo que no es la contradicción, sino la combinación e intracombinación la que subyace en la relación de los elementos de la realidad, en complementación equilibrada y consensual, con pleno respeto a la identidad del otro.

Antes que nada queremos señalar que los conceptos que vamos a tratar aquí no son étnicos; es decir, no se corresponden con alguna configuración bio-cultural específica. Todos los seres humanos del planeta pueden poseer o adscribirse a una u otra filosofía, independientemente de su raza, color o etnia. A pesar de que la filosofía de la unidad con la naturaleza es más visible en las comunidades indígenas del Tercer Mundo americano, asiático y africano, también está presente en individuos que racialmente no pueden ser considerados indígenas; por ejemplo, en europeos o descendientes de europeos. Al mismo tiempo, no todos los individuos de las comunidades indígenas del mundo entero condicen con el sentimiento de unidad con la naturaleza y hace ya mucho tiempo que muchos de ellos han asumido la visión de mundo occidental: cristiana, racionalista y fragmentada que 
Europa exportó desde la primera colonización.

La filosofía de la unidad - una propuesta filosófica elaborada por el Amauta inca José Illescas $^{11}$ - es una manera ancestral de pensar y sentir que la realidad es energía vibratoria que se concentra y desconcentra en cada uno (he ahí la semejanza) con una particular velocidad de vibración, frecuencia de onda, lo cual hace la diferencia. Por esa concepción energética, nada de lo que existe puede ser concebido como muerto: todo es vibratorio; ergo, todo elemento de la realidad es un ser vivo. Ello rompe con las dicotomías típicas de la filosofía de la no-unidad: entre lo vivo y lo muerto, o lo orgánico y lo inorgánico, o lo biológico y lo no-biológico. Todo tiene vida, inteligencia y autodeterminación; por eso es mejor no hablar de elementos, sino de seres semejantes-diferentes, sean humanos, animales, vegetales o minerales. La diferencia entre un humano, un lobo, una piedra y una rosa no expresa ninguna jerarquía _ni biológica ni de sentimiento ni de razonamiento_, ya que está combinada con una semejanza: la de ser todos ellos la misma realidad natural, expresada en cada uno con su propia especificidad.

La filosofía de la no-unidad establece la diferencia que separa, que señala que uno no es el otro; de ahí deviene la jerarquía y el antagonismo, la subordinación y la lucha dialéctica entre pares de opuestos contradictorios. Se puede concebir que uno se convierta en el otro o que el uno genere al otro y viceversa, pero no se puede entender desde estos moldes mentales que el uno es el otro y viceversa. La filosofía de la no-unidad, en cambio, enfatiza la diferencia-semejanza que no admite jerarquías antropo-etnocéntricas ni secuencialidades lineales de causas y efectos, pues uno contiene al otro: es el otro, por su semejanza, y, al mismo tiempo, es sí mismo (no es el otro), por su diferencia.

Siendo la realidad un todo entrelazado, donde ningún elemento está separado ni mucho menos por encima o por debajo de otro, se asume que el humano está unido a la realidad, pero no con lazos de compañía, sino con combinaciones e intracombinaciones que amarran, tejen, penetran e interpenetran todo con todo. Por la combinación, se da la interrelación en la que uno y otro se inter-penetran. La intra-combinación es la intra-relación o proceso que ocurre al interior de cada uno, por el cual se asimila-desasimila al otro interpenetrado, alcanzando así el pleno desenvolvimiento como individuo. Combinación e intracombinación no son dos etapas sucesivas, sino simultáneas, que rompen con la dicotomía externo-interno. Por la combinación e intra-combinación, lo externo se hace interno y viceversa. Se toma selectivamente del otro lo que potencia la propia identidad, asegurando la auto-generación de cada uno sin perder la identidad ni el equilibrio con el entorno.

\footnotetext{
${ }^{11}$ Este tema está desarrollado extensamente en: Mazorco 2008. Un resumen elaborado por Mazorco bajo el título de "Bases filosóficas para hacer otro mundo posible" puede encontrarse en Polis $\mathrm{N}^{\circ} 17$, Revista de la Universidad Bolivariana, Santiago
} 
No tiene que darse primero uno (la causa) para que luego exista el otro (la consecuencia). Ambos coexisten combinados e intracombinados y no ejercen ningún determinismo del uno sobre el otro. Uno y otro se autodeterminan en complementación. De esa manera, la naturaleza no es concebida como una externalidad, porque se incluye o se combina-intracombina en lo interno de cada uno (Gonzales e Illescas 2003).

Cada ser de la realidad: un animal, una estrella, una montaña, una planta es, por tanto, un ser vivo, inteligente, sensitivo, volitivo, imaginativo y con sabiduría; un hermanohermana, una madre-padre, un amigo-amiga. De ninguna manera es un «recurso» natural que pueda ser explotado sostenible o insosteniblemente. Sin embargo, estas inter e intrarelaciones no implican ninguna reciprocidad ni redistribución sustentada en la solidaridad; éste es un elemento ideológico que occidente ha introducido y los indígenas han asimilado con alienación para denotar que los originarios acumulaban riqueza y la redistribuían al puro estilo capitalista. Nada más alejado del sentimiento de unidad, pues la solidaridad, la reciprocidad y la redistribución no se basan en el equilibrio simétrico, sino que admiten una inter-relación en la que uno da aquello que ha acumulado. Pero en la unidad no hay desequilibrios que produzcan acumulación de un lado y escasez de otro (Gonzales e Illescas 2003).

La clave de la combinación e intracombinación entre seres es: la complementariedad, el equilibrio, el consenso y el respeto a la identidad del otro. En este sentido, no puede el humano hacer utilización inconsulta, no consensuada, no complementaria y no equilibrada de ningún otro ser humano, natural y/o cósmico, pues, en ese caso, no estaría respetando la identidad del otro.

\section{El punto de mutación}

La autodeterminación y la complementación se apuntan desde las dos filosofías como los elementos clave para el cambio paradigmático que haga factible equilibrar las injusticias de la sociedad capitalista. Sin embargo, estos principios han sido adoptados por el mundo empresarial y por la teoría económico-administrativa para potenciar la economía de mercado y profundizar las contradicciones del sistema capitalista. De hecho, la complementación es asumida de diferente manera, dependiendo de las concepciones de mundo en que se inserte. Para la filosofía occidental, que funda las relaciones sociales y económicas en la dicotomía y la jerarquía, la complementación se perfila como la suma de fuerzas entre empresas para enfrentar al enemigo en el mercado: tiene una función netamente competitiva y reproduce el equilibrio asimétrico ${ }^{\mathbf{1 2}}$ por el que unos acumulan a

\footnotetext{
12 Antes que el término: desequilibrios, preferimos usar: equilibrios asimétricos, para señalar que en la realidad no existen desequilibrios, sino que se dan distintas modalidades de equilibrio. Desde la filosofía de la unidad se concibe que el equilibrio es la esencia de la realidad. «Sea cual fuese el tipo de modalidad social en la que vivamos, sea en la Unidad o en la no Unidad, la realidad siempre está en equilibrio. Sin embargo, en la no Unidad, lo humano separado de su dimensión natural y cósmica se ha alienado y enajenado al extremo que podemos decir que lo ha desequilibrado todo o, en términos más apropiados, que vive la realidad en un equilibrio no óptimo». (Mazorco 2008).
} 
costa de que otros desacumulen y desaparezcan.

De otro lado, para la filosofía que sustenta la unidad del hombre con la naturaleza, el cosmos y la totalidad de la realidad la complementación resulta de la combinación equilibrada y consensuada entre todos los elementos de la realidad y no sólo entre humanos. Al darse con pleno respeto a la identidad del otro, la complementación asegura el pleno desenvolvimiento de la identidad de cada uno en equilibrio con cada otro. Esta complementación es simétrica y demuestra que es posible encontrar adaptaciones «mejor» equilibradas que las generadas por la complementación en competencia. Mientras ésta supone una contienda que necesariamente destruye uno de los organismos (el más débil), la complementación simétrica asegura el mejor desenvolvimiento de ambos: hay un beneficio mutuo. Es decir, ambas modalidades son adaptaciones al entorno, pero una es asimétrica y crea un equilibrio no óptimo, pues genera destrucción, y la otra es simétrica, equilibrando óptimamente a los participantes: no hay uno débil y otro fuerte.

Entonces, la clave del cambio paradigmático está en encontrar el punto de mutación en el que los procesos adaptativos que rigen la transformación de la realidad puedan trocarse de asimétricos (es decir, competitivos y antagónicos) en simétricos (es decir, consensuales y con pleno respeto a la identidad del otro), permitiendo autogenerar una sociedad-economía equilibrada óptimamente. Sin embargo, no queremos decir con estas palabras que exista un equilibrio «mejor» que otro, ni, mucho menos, que una modalidad social-civilizacional deba ser reemplazada por otra «mejor». En principio, creemos que la inter e intra-culturalidad admite la convivencia armónica de distintas modalidades sociales. En cuanto al término: mejor, lo colocamos entre comillas para señalar sus limitaciones, ya que no consideramos que en la realidad haya mejores o peores equilibrios. En su permanente complementación con autodeterminación cada unidad de vida se equilibra permanentemente hacia fuera y hacia dentro, sin que estos equilibrios denoten una condición o estadio mejor o superior a otro, en términos de la totalidad de la realidad. Caro que cuando miramos al mundo con el ojo humano solemos -muy sesgadamente, por ciertoconsiderar mejores o peores equilibrios en función de cómo éstos puedan afectar la supervivencia de la especie humana. Esto significa, por ejemplo, que la denominada crisis medioambiental es una respuesta adaptativa del entorno natural ante la actividad humana capitalista y aporta altas probabilidades para la desaparición de la especie humana. No obstante, para la naturaleza y el cosmos no es más que una nueva forma de equilibrio interno y externo que les otorga coherencia con las acciones productivas, con las experimentaciones científicas y los conflictos armados que les detonan ajustes estructurales complementarios. Pero también significa que es factible al ser humano auto-determinar conductas que se adapten al medioambiente natural y cosmológico, generando equilibrios óptimos, es decir, simétricos, más favorables para la supervivencia de la humanidad.

Creemos firmemente que la condición de posibilidad que buscamos viene dada por el 
fundamento filosófico que no dicotomiza al ser humano de la naturaleza y no es antropocéntrico. Es verdad que, por ejemplo, el enfoque de desarrollo humano y sostenible es portador de una nueva concepción de la relación hombre/naturaleza, ya que promueve el cuidado del medioambiente. También la economía solidaria esboza la "transformación humanizadora y armoniosa de la naturaleza", tal que no deteriore el medioambiente y lo preserve para generaciones futuras (Razeto 1999). Sin embargo, y aunque proyecta la transformación del ser humano en base a nuevos modos de pensar, sentir y hacer, retoma para ello los viejos valores de la revolución burguesa: solidaridad y fraternidad, con lo cual, es poco lo que se está cambiando. Si bien invierte la fórmula capitalista al poner al hombre y la comunidad por encima del capital, preserva el antropocentrismo del modelo dominante, porque también los pone por encima de la naturaleza.

Es por eso que los valores humanistas incorporados a la economía no constituyen un nuevo paradigma. Simplemente flexibilizan el sistema para adaptarlo a un contexto convulsivo, sin cambiar las bases filosóficas que lo fundan; es decir, mantienen intacta la separación hombre/naturaleza y el ser humano salvaguarda el centro del mundo. La naturaleza sigue siendo vista como un cúmulo de recursos puestos al servicio del hombre. Por tanto, no condice con la filosofía de muchos individuos y colectivos del planeta que sienten y piensan la unidad hombre/naturaleza y pueden proveernos los marcos conceptuales y procedimentales para constituir nuevos paradigmas que soporten el cambio de la condición humana y contribuyan a transformar las injusticias del mundo que hoy vivimos.

La filosofía de la unidad busca la emancipación del ser humano: su descolonización, no importa a cuál colectivo étnico corresponda, a partir de una propuesta no antropocéntrica que concibe al hombre y a la mujer como un Ser Humano Integral; es decir: humano, natural y cósmico, parte y continente de la realidad total. Este Ser Humano Integral exige, para su autodeterminación, que se abran espacios inter e intraculturales en los que le sea posible otra forma de hablar, de hacer ciencia, economía, juricidad, culturalidad, política, arte, etc.

\section{La economía inter e intracultural}

Las preguntas que traemos a colación son: ¿Puede la ciencia económica abrir espacios teóricos y metodológicos para dar cabida a prácticas productivas y comerciales que responden a otra visión de ser humano y de naturaleza? ¿Es posible concebir una plurieconomía que acepte la presencia de alternativas económicas que convivan y se complementen sin asimetrías con la economía capitalista? En definitiva, nuestro cuestionamiento destaca la unilateralidad paradigmática de los enfoques económicos vigentes, tanto el convencional como los de nuevo corte humanista, y apunta a abrir espacios para una economía inter e intracultural.

La interculturalidad que propone la postmodernidad es una relación entre diferentes, 
en la que se respetan los desacuerdos en aspectos formales, que no pasan de ser folclóricos, pero se imponen verticalmente los acuerdos en la esencia de la actividad económica: el mercado, la competitividad y la acumulación de capital y ganancia. De esa manera, la identidad cultural del otro, aunque mantenga sus particularidades de forma, es torcida en su esencia y sucumbe a la imposición de los códigos capitalistas.

Desde el punto de vista de las filosofías que no imaginan relaciones mercantiles con la naturaleza ni con los seres humanos, no se puede concebir que se declare el respeto a la diversidad cuando todos son conminados a integrarse al mercado, siendo que el mercado trasunta una filosofía de vida que establece un relacionamiento utilitario de la naturaleza, totalmente incompatible con el pensamiento y el sentimiento de aquellos que la ven como una madre.

Desde el sentimiento de unidad con la realidad, la inter-culturalidad no puede verse separada de la intra-culturalidad. La intra-culturalidad significa que cada cultura afirma y consolida su esencia pese a los cambios de forma que puede asumir por la relación horizontal con otras culturas (o inter-culturalidad). El respeto a la identidad del otro, que sólo puede ser ejecutado estableciendo con él relaciones equilibradas, complementarias y consensuadas, es la base de la inter e intra-culturalidad y la descolonización que, a nuestro entender, deben regir las relaciones entre hombres y mujeres y entre éstos y la naturaleza, el cosmos y la totalidad de la realidad.

La inter e intraculturalidad supone, entonces, la convivencia armónica de plurales culturas, economías, juricidades, cientificidades, filosofias, etc. En lo económico, podemos decir que la pluralidad admite dos modalidades básicas. Una es la occidental, o capitalista de mercado, basada en la explotación del otro: humano, natural o cósmico. Es la dominante y realiza una actividad productiva que se vale de la naturaleza y del hombre como instrumentos útiles para la elaboración de objetos de intercambio mercantil y para la acumulación de capital. El individuo occidental ha asumido una posición jerárquica y dominante que redunda en la reducción de todo lo natural a la condición de «recurso», «instrumento», «activo» o «capital», útil para obtener lucro y rentabilidad.

Sea cual fuere la concepción económica: o bien la economía convencional orientada hacia fines materiales de riqueza y crecimiento, en la que prima el interés individual y la competencia, o bien los nuevos enfoques humanistas que, antes que el puro crecimiento económico material, persiguen la mejora de la calidad de vida de las personas, preservando el medioambiente natural e integrando a la sociedad con valores de solidaridad y cooperación, ambas están preñadas de antropocentrismo: es el hombre quien determina la evolución del entorno sin que él mismo se vea sometido a ninguna transformación identitaria en este proceso.

El antropocentrismo es parte del tronco paradigmático eurocéntrico, que se enmarca 
en la filosofía de no-unidad del ser humano con la realidad. A partir de una escisión primera (yo/mundo) surgen todas las demás particiones, como ser: naturaleza-cultura, sujeto-objeto, vivo-muerto, mente-cuerpo, materia-espíritu. Todas estas dicotomías sustentan la propuesta utilitarista que ve a todos los seres de la tierra y la realidad como recursos que pueden alimentar el consumo humano y el consumo del gran capital; pero es la dicotomía naturaleza-cultura la que mejor la refleja. La cultura se restringe únicamente al ser humano, como la capacidad que éste tiene para transformar la naturaleza y utilizarla para su desenvolvimiento mediante la razón y el cerebro. En ese sentido, se cree antropocéntricamente que la cultura le otorga al ser humano libertad, en el entendido de que no está determinado por la evolución natural, y le permite escabullirse del mundo programático de la biología por medio de la mente y la conciencia En cambio, la naturaleza y, contenida en ella, los animales, los vegetales y los seres cosmológicos no son concebidos como hacedores de cultura. (Mazorco 2008).

Esto no condice con aquellas culturas tradicionales que practican, no una «economía de subsistencia», como se les imputa con un criterio subalternizante, sino una «economía de autodeterminación». En tanto se conciben parte de la naturaleza, se sienten hermanadas, emparentadas y amigas de todos los seres que la integran, sean o no humanos, a los que reconocen vitalidad, inteligencia y emocionalidad. Los hombres y mujeres que piensan y sienten de esta manera no adoptan criterios paternalistas de uso cuidadoso de la naturaleza, pues no la consideran como un almacén de simples «recursos» disponibles por el hombre.

La «economía de autodeterminación» está signada por el equilibrio con la naturaleza. Se considera a la Tierra como una madre que provee y atiende a sus hijos a cambio de respeto y cuidado. Al ser la naturaleza un gran organismo vivo, cada uno de sus elementos y sus diversas combinaciones son también seres vivos, con los cuales se debe consensuar una relación que no es productiva, sino de mutua crianza, en equilibrio complementario y con total respeto a la identidad de cada elemento, que no es elemento, en tanto es padremadre-hermano-hermana del hombre y de la mujer.

Bajo esta concepción y vivencia de la realidad, en la cual la complementación no es compatible con la competencia, las relaciones sociales no son exclusivamente entre hombres y mujeres, sino que incluyen a todos los seres naturales, con los que se dialoga respetuosamente para coordinar las acciones productivas, que no son unidireccionales ni verticales. Supone la unificación de la dimensión productiva con la social y la natural, convirtiendo al trabajo en una modalidad de existencia que integra todas las dimensiones de vida humana, natural y social. (Arispe 2007). De ese modo, la economía no puede verse como una construcción humana, sino como la auto-organización conjunta, en complementación entre lo humano, lo natural y lo cósmico.

Bajo esos parámetros, la concepción occidental de producción, distribución y consumo cambia radicalmente. Modificar la naturaleza a través de la producción es, en 
estos casos, una transformación mutua, respetuosa y consensuada para mantener los equilibrios entre unos y otros, así como los internos, al interior de cada uno. La distribución no se basa en el intercambio de mercancías de forma competitiva, sino en el intercambio complementario y cargado de relaciones culturales de seres vivos, sean estos humanos, naturales o cósmicos. Finalmente, el consumo va más allá de la ingestión o aprovechamiento de un producto, pues reside en un proceso de combinación e intracombinación complementaria del ser humano y el ser vivo denominado «producto» por occidente, en el que cada uno se convierte en el otro. (Arispe 2007).

Es decir, la concepción económica originaria no es antropocéntrica y no radica en el mercado ni en la competencia. Producir es un hacer todos juntos con la naturaleza y la comunidad, con la ayuda complementaria y con el consenso de cada uno de los seres humanos y no humanos que intervienen, con respeto a la identidad de cada uno-otro, sin pretensión de hegemonismo de uno sobre el otro, sin concebir la explotación ni la utilización inconsulta y no complementaria, cuidando los propios equilibrios internos y los equilibrios con el entorno social, medioambiental, natural, planetario, cósmico y total. No se trata de una actividad productiva-económica, sino de un hacer integral que abarca toda la condición de existencia del ser humano unido a la naturaleza y a la totalidad de la realidad (Gonzáles e Illescas 2003).

Por el sentimiento y pensamiento de estar ligado a la naturaleza y ser la naturaleza misma, sin dicotomías entre el individuo y su entorno, y sin separación entre el productor y su producto, ni los elementos naturales ni el trabajo humano son pensados como recursos para la producción, ni los bienes producidos son considerados como objetos inertes para el intercambio y el consumo. Aún el producto final de un hacer todos juntos, el cual no es pensado ni sentido como mercancía, sino como un ser autónomo, es un ser vivo que se coproduce simultáneamente con el ser humano, en una relación complementaria y equilibrada entre el productor y los seres (no recursos) que participan en el proceso de producción y que tienen su propio derecho a existir en equilibrio con el medioambiente, en el cual están incluidos los humanos.

La inter e intraculturalidad no es una propuesta utópica que olvida las relaciones de poder que impregnan los mercados y las sociedades. En ese entendido, el equilibrio entre culturas sólo puede darse cuando se han depuesto las relaciones de dominación y las culturas subalternas puedan, con autonomía y respeto mutuo entre diversas identidades, expresarse en el ámbito simbólico, en el económico, político, social, científico, tecnológico, jurídico, religioso y artístico.

\section{Conclusión}

Bajo un manto humanista de centramiento en las necesidades del hombre y de respeto a la vocación particular de desarrollo de las identidades sistemáticamente sometidas y 
exfoliadas por la voracidad del capital, las energías ideológicas del sistema persiguen que los marginados y excluidos acepten que el capitalismo y su economía de mercado son la única alternativa, y declinen la lucha por otro mundo posible mientras creen que están preservando sus valores culturales.

El estilo de producción, oferta y consumo que ofrece la lógica capitalista de mercado es restrictivo de otras visiones insertas en la diversidad de identidades culturales que existen en el mundo. Si es que vamos a atenernos a la multiculturalidad proclamada en la postmodernidad, no deberíamos tratar de integrar la cultura de producción local a los parámetros de mercado, que es lo que el paradigma de desarrollo, en todas sus versiones, propone. Si bien esta integración pretende ser lograda a partir de un discurso de desarrollo humano y economía solidaria que respeta la interculturalidad de visiones y modos de producción, en la realidad la visión que prevalece es la de mercado con todos los códigos que le son congénitos: desarrollo, competitividad, calidad, eficiencia y un largo etcétera. Es decir, la propuesta es monocultural e impositiva; niega la intra-culturalidad. La lógica integradora consiste precisamente en disolver otras visiones de producción y consumo para asimilarlas a la lógica mercantilista.

Aunque en la actualidad occidente promueve la complementación y la solidaridad como valores rectores de los procesos económicos, ese discurso no es creíble en la medida en que el mercado sigue siendo el eje articulador de las relaciones entre todos los seres humanos y no humanos del planeta. Tanto el desarrollo humano como la economía solidaria pecan de limitaciones que provienen de un substrato filosófico que mantiene inalterada la esencia del sistema capitalista. El calificativo de humano o solidario, o la conformación de redes sinérgicas cooperativas, no altera la índole del mercado. El mercado es un código de la cultura occidental que expresa una filosofía, una concepción y una vivencia de la realidad que parte de la separación entre el hombre y la naturaleza, que convierte a ésta en objeto de explotación, uso e intercambio, sin ningún respeto ni solidaridad hacia ella, y define las relaciones humanas como un campo de lucha por la vida, en la que no triunfa el más solidario, sino el más competitivo; es decir, el más peleador. El mercado es la creación de una cultura pugilística que, aunque decida ponerse guantes de seda, no elimina por ello la contienda entre antagónicos. Más bien, la perfecciona, desarrollando instrumentos de alto calibre que, por poco accesibles a la mayoría de los contendientes, aseguran el triunfo de unos pocos, que cada vez son menos. Así, las empresas de éxito en la globalización no son las que juegan limpiamente el libre juego de la oferta y de la demanda, utilizando recursos comerciales como la calidad del producto y el precio ventajoso, como establece la teoría del marketing, sino aquellas organizaciones asistidas por reglas negociadas políticamente. En efecto, con el modelo neo-liberal el mercado dejó de ser un juego primariamente comercial para constituirse en una trama eminentemente política que sólo puede ser digitada por quienes tienen el poder de controlar la economía mundial. 
El llamado social a hacer «otro mundo posible» requiere la reconfiguración paradigmática de las ciencias económicas, entre otras, para dar cabida y potencial de desenvolvimiento a nuestros pequeños empresarios, campesinos e indígenas en condiciones no asimétricas y con plena autodeterminación; es decir, sin tener que someterse a la modalidad de producción y comercialización que el sistema capitalista impone. En esa línea, hacemos un llamado a la reflexión crítica y propositiva para aportar teóricamente a la constitución de una sociedad pluricultural y plurieconómica, en la que puedan autodeterminarse distintas modalidades de existencia (no sólo de trabajo) en función de las diversas cosmovisiones que lo pueblan.

La autonomía (auto-regulación) y la complementación no son contradictorias. Son, más bien, las realidades de la inter e intraculturalidad que hacen posible una interculturalidad no asimétrica, fundada en la asimilación selectiva y auto-decidida de aquellos rasgos del otro que sirven para potenciar la propia identidad. 


\section{Bibliografía}

Alonso Falcón, Randy (2008), "Radiografía del caos", en http://elinformador.wordpress.com/2008/10/18/radiografia-del-caos/, consultado en oct-2008.

Arispe, Sergio; Rivera Maya y Mazorco Graciela (2007), "Dicotomías étnicas y filosóficas en la lucha por la descolonización", en Polis $N^{\circ} 18$, Revista de la Universidad Bolivariana, Santiago.

Bekerman, Marta y Cataife, Guido (2004), "Encadenamientos productivos: impactos sobre el desarrollo de los paìses perifèricos", en Teoría y Práctica del Enfoque de Cadenas Globales de Mercancías en América Latina, PROMEC-UMSS, Cochabamba.

Camargo, María G. (2007), Instituto de Geografía y Conservación de Recursos Naturales. Universidad de Los Andes, Mérida-Venezuela, "Desarrollo Endógeno Local", en http://209.85.165.104/search?q=cache:RcitbxqNldwJ:gabrielaterritorio. blogspot.com/20/07/04/ desarrollo-endogeno-locali.html+\%22fomenta+los+procesos+ de+acumulaci\%C3\%B3n+en+ las+grandes $+\% 22 \& \mathrm{hl}=\mathrm{es} \& \mathrm{ct}=\mathrm{clnk} \& \mathrm{~cd}=1 \& \mathrm{gl}=\mathrm{us}$, consultado en ago-2007.

CCD - COOPERACIÓN, CONOCIMIENTO Y DESARROLLO (s/f.); http://ccdckd.cebem.org/pages/tophum/index_esp.php; consultado el 18-09-08.

"Desarrollo Endógeno: desde adentro, desde la Venezuela profunda.", en http://209.85.165.104/search?q=cache:glYIP-

W3SvkJ:www.gobiernoenlinea.ve/misc-

view/sharedfiles/Desarrollo_endogeno_1.pdf+\%22La+integraci\%C3\%B3n+econ\%C

3\%B3mica: + en+donde+un+sistema $\% 22 \& \mathrm{hl}=$ es \&ct=clnk\&cd=1\&gl=us; consultado en ago-2007.

Gonzáles, Tatiana e Illescas, José (2003), Acerca de nuestra identidad de sociedad, de cultura y de civilización originaria, Ediciones Tukuy Riqch'arina, Cochabamba.

Hawking, Stephen (1997). Historia del Tiempo: del big bang a los agujeros negros. Grijalbo Mondadori, Barcelona.

Kimura, Motoo (1991), "Darwin se equivocó: la suerte es la clave de la evolución"; en: Sorman, Guy. Los verdaderos pensadores de nuestro tiempo. Seix Barral, Barcelona. 
Mazorco, Graciela (2008), Filosofía, Ciencia y Saber Andino: Bases ontológicas, gnoseológicas y epistemológicas de la inter e intra-culturalidad, 2a. Edición, Editorial Universidad Bolivariana, Santiago.

Pelupessy, Wim (2002), "Bolivia en el Mercosur: Estudio de caso de la industria del cuero", en La Gestión Económica Ambiental en las Cadenas Globales de Mercancías en Bolivia, IESE-PROMEC-IVO, Cochabamba.

Peña Sánchez, A.R. (2006), "Teorías explicativas de las disparidades económicas espaciales", en Las disparidades económicas intrarregionales en Andalucía, Tesis doctoral accesible a texto completo en http://www.eumed.net/tesis/2006/arps/, consultado en ago-2007.

Pilonieta, Claudia y Ochoa, Alejandro (s/f), Universidad de Los Andes. Mérida. Venezuela, "El Desarrollo Endógeno Sustentable. Una Aproximacion Conceptual", en http://64.233.169.104/ search?q=cache:vvsry7eRBv8J:www.saber.ula.ve/cgiwin/be_alex.exe\%3FDocumento $\%$

3DT016300003259/2\%26term_termino_2\%3De:/alexandr/db/ssaber/Edocs/centros_i nvestigacion/csi/publicaciones/monografias/desarrollo_endogeno/capitulo1.pdf\%26te rm_termino_3\%3D\%26Nombrebd\%3Dsaber+\%22debe+tener+su+origen+desde+el+i nterior + de + la + misma $\% 22 \& \mathrm{hl}=\mathrm{es} \& \mathrm{ct}=\mathrm{clnk} \& \mathrm{~cd}=1 \& \mathrm{gl}=$ bo\&client=firefox $-\mathrm{a}$;

consultado en ago-2007.

PNUD - $\quad$ Desarrollo Humano (s/f.); http://www.desarrollohumano.org.ar/Glosario.asp; consultado el 18-09-08.

Prigogine, Ilya (1991), "El orden nació del caos", en: Sorman, Guy. Los verdaderos pensadores de nuestro tiempo, Seix Barral, Barcelona.

Ramírez, Alejandra (2003), "Cultura, calidad de vida y desarrollo", en Temas de discusión en torno a la idea de desarrollo, CESU-UMSS, Cochabamba.

Razeto, Luis (1999), "La economía de solidaridad: concepto, realidad y proyecto", en la revista Persona y Sociedad, Volumen XIII, No 2 Agosto de 1999, Santiago de Chile, en http://www.neticoop.org.uy/article314.html, consultado en ago-2007.

Sachs, Wolfang (1997), El diccionario del desarrollo. Una guía del conocimiento como poder, CAI Centro de Aprendizaje Intercultural, Cochabamba.

Sánchez, Vanesa (2004), "Misión Vuelvan Caras, una estrategia de desarrollo nacional",

http://209.85.165.104/search?q=cache:SrKJgkCkWPoJ:www.aporrealos.org/actualida d/a8497.html+el+desarrollo+est\%C3\%A9+relacionado+con+la+cultura+de+cada+pu eblo. \&hl=es\&ct=clnk\&cd=1\&gl=es, consultado en ago-2007.

Sorman, Guy (1991), Los verdaderos pensadores de nuestro tiempo, Seix Barral, Barcelona. 
Tapia, Marcelino (2003), “'Los intangibles y su incidencia en los procesos de cambio social", en Temas de discusión en torno a la idea de desarrollo, CESU-UMSS; Cochabamba.

Zegada, Oscar, comp. (2004), Reflexionando la economía y la sociedad, PROMECUMSS, Cochabamba. 